\title{
Preparation of yttrium citrate by the reaction of yttrium hydroxide with sodium citrate
}

\author{
Władysław Janusz, Ewa Skwarek, Dariusz Sternik \\ Faculty of Chemistry, Marie Curie- Sklodowska University, Lublin \\ Corresponding author: e-mail ewunias@hektor.umcs.lublin.pl
}

\begin{abstract}
A method of obtaining yttrium citrate by transformation of freshly precipitated yttrium hydroxide in the solutions of sodium citrate under hydrothermal conditions has been proposed. To determine the synthesis time, transformation kinetics consisted in by taking the solid samples for the $\mathrm{C}$ and $\mathrm{H}$ contents analysis after 6, 12, 24, 48 and 72 hours of synthesis. Simultaneously these samples were subjected to the thermogravimetric analysis. As follows from the thermogravimetric analysis adsorption of citrate dihydrate on yttrium hydroxide is observed in the initial period up to 24 hours. Later the yttrium citrate dihydrate is formed. The thermogravimetric analysis of the final product i.e. amorphous yttrium citrate showed that the decomposition/oxidation of the sample occurs in six stages the particle size analysis method of static light scattering showed that $45 \%$ of the particles had a diameter of $0.1-0.9 \mu \mathrm{m}$ and $55 \%$ of particles with sizes from 0.9 to $5 \mu \mathrm{m}$.
\end{abstract}

Keywords: yttrium citrate synthesis, CHN, TGA, particle size

\section{Introduction}

Yttrium citrate (YCit) belongs to the compounds whose synthesis, composition, structure and properties are not well described in literature. Few studies describe the method of obtaining yttrium citrate through the precipitation reaction from a solution of yttrium chloride and citrate salts (Babeshkina et al., 1996a, Babeshkina et al., 1996b, Petrova et al., 2006). The preparations obtained as a result of these syntheses differ in composition. In the case of preparations obtained by Babeshkina et al, the crystallographic structure was characterized by specifying the location and intensity of the peaks from the diffraction pattern (Babeshkina et al., 1996b). Petrova and Todorovsky described the synthesis of amorphous yttrium citrate $\mathrm{Y}$ of the composition $\mathrm{Y}$ (HCit) $1.53 .5 \mathrm{H}_{2} \mathrm{O}$ obtained by the sol: gel method (Petrova et al., 2006). Yttrium citrate was also obtained as a precursor for the production of various functional coatings of yttrium oxide, doped with rare earth elements (Chen et al., 2017, Zhong et al., 2009, Mangalarajaa et al., 2008). Additionally, yttrium [ $\left.{ }^{90} \mathrm{Y}\right]$ radiolabelled citrate radiocolloids are used to treat many joint ailments by radiosynovectomy (Mangalarajaa et al., 2000).

The method of radiosynovectomy involves the injection of radiocolloid label with the beta-radiation emitting a radionuclide into a diseased joint where the emitted radiation destroys the outer layers of the membrane and reduces the number of blood vessels in it. The European Association of Nuclear Medicine in the Guideline for Radiosynovectomy mentions the following radiocolloids: ${ }^{90} \mathrm{Y}$ silicate or citrate, ${ }^{186}$ Re sulphide and ${ }^{169} \mathrm{Er}$ citrate (Eur. J. Nucl. Med.,). As reported in the literature yttrium citrate was obtained by reacting citric acid with ${ }^{90} \mathrm{Y}$ ions eluted from the ion exchanger in order to separate it from the parent radionuclide ${ }^{90} \mathrm{Sr}$ (Bowen et al., 1975). Yttrium citrate was obtained by mixing 0.1 $\mathrm{mol} / \mathrm{dm}^{3}$ of yttrium chloride with trisodium citrate while maintaining the $\mathrm{pH}$ in the range of $7-8$. The precipitate obtained by this method contained a variable number of water molecules from 1 to 3 (Gmelin 1984). Another method was used in the synthesis of lanthanum citrate and a number of lanthanide citrates, which were obtained by reacting oxide with citric acid (Baggio et al., 2004, Zhou et al., 2008). 
Preparation of monodisperse colloids is based on the control of the nucleation process, crystal growth, dissolution of recrystallization and aggregation (Viswanatha et al, 2007). Monodisperse particles have a uniform size, shape and composition, and their particle size distribution is characterized by a relative standard deviation smaller than 10\% (Sugimoto 2002). Many methods of preparation of monodisperse colloidal systems of various compounds or elements were described in the literature. The most common methods including metal sulfides and oxides can be divided into precipitation of from homogeneous solutions, phase transformations and aerosol reactions (Matijevic 1986). As for the homogeneous solution to obtain homogeneous particles, forced hydrolysis, controlled anion release or controlled cation release were applied. Research on colloidal systems can be very helpful in optimizing the synthesis conddions of new compounds used in radiopharmacy such as yttrium [90Y] citrate. The herein presented approach to the synthesis of yttrium citrate is novel and was not explored by other authors.

In this paper the attempts were made to optimize the conditions for the synthesis of monodisperse yttrium citrate by transforming yttrium hydroxide to yttrium citrate in the reaction of freshly precipitated yttrium hydroxide with sodium citrate using the assumptions and thermodynamic analysis similar to the proposed for determination of the surface composition of the $\mathrm{ZnO} / \mathrm{Zn}(\mathrm{OH})_{1.6} \mathrm{Cl}_{0.4}$ system by Block and de Bruyn (Block et al., 1970). To determine the $\mathrm{pH}$ range in which yttrium citrate is more stable than yttrium hydroxide, the solubility products of amorphous yttrium hydroxide and the product of of yttrium citrate solubility were considered:

$$
\begin{aligned}
\mathrm{Y}(\mathrm{OH})_{3(\mathrm{am})} & \leftrightarrow \mathrm{Y}^{3+}+3 \mathrm{OH}^{-} \quad \mathrm{pK}_{\mathrm{Y}(\mathrm{OH}) 3(\mathrm{am})}=22.8 \text { (Feitknecht and Schindler, 1963) } \\
& \mathrm{YCit} \leftrightarrow \mathrm{Y}^{3+}+\mathrm{Cit}^{3-} \quad \mathrm{pK}_{\mathrm{YCit}(\mathrm{s})}=11.03 \quad \text { (Gmelin, 1984) }
\end{aligned}
$$

The equilibrium constant of the reaction of yttrium hydroxide into transformation yttrium citrate is equal to:

$$
\mathrm{Y}(\mathrm{OH})_{3(\mathrm{am})}+\mathrm{Cit}^{3-} \leftrightarrow \mathrm{YCit}_{\mathrm{s}}+3 \mathrm{OH}^{-} \quad \mathrm{pK}_{\mathrm{I}}=11.77
$$

To determine the effect of citrate ion concentration on $\mathrm{pH}$ of the transformation of amorphous yttrium hydroxide into yttrium citrate, the thermodynamic equilibria of yttrium hydroxide precipitation (index I) and yttrium citrate (index II) were considered:

$$
\begin{gathered}
\mu_{I}^{0}(\text { solid })+R T \ln (x)=\mu_{I}^{0}(\text { soln. })+R T \ln \left(a_{Y 3+} * a_{O H}^{3}\right) \\
\mu_{I I}^{0}(\text { solid })+R T \ln (1-x)=\mu_{I I}^{0}(\text { soln. })+R T \ln \left(a_{Y 3+} * a_{C i t}\right)
\end{gathered}
$$

where $x$ is the molar fraction of $Y(\mathrm{OH})_{3(\mathrm{~s})}$

After subtracting equation 1 from equation 2, there is obtained:

$$
R T \ln (L)=\left[\mu_{I I}^{0}(\text { soln. })-\mu_{I I}^{0}(\text { solid })\right]-\left[\mu_{I}^{0}(\text { soln. })-\mu_{I}^{0}(\text { solid })\right]+R T \ln \left(a_{C i t+} / a_{O H}^{3}\right)
$$

where:

$$
L=\frac{(1-x)}{x}
$$

Substituting the equation for solubility products into the equation:

$$
\begin{gathered}
2.3 R T p K_{Y(O H) 3(a m)}=\mu_{I I(\text { soln })}^{0}-\mu_{I I(\text { solid })}^{0} \\
2.3 R T p K_{Y C i t}=\mu_{I(\text { soln })}^{0}-\mu_{I(\text { solid })}^{0}
\end{gathered}
$$

and including the solubility product values there is obtained:

$$
\begin{gathered}
\log (L)=-11,77+3 * p O H-p \mathrm{Cit}^{3-} \\
p L=-30,23+3 * p H+p \mathrm{Cit}^{3-}
\end{gathered}
$$

The relationship of the molar fraction of yttrium citrate calculated from the above equation, as a function of $\mathrm{pH}$ for various concentrations of citrate ions is presented in Fig. 1.

Fig. 1 shows the relationship of the molar fraction of yttrium citrate in the system of yttrium citrate - yttrium hydroxide as a function of $\mathrm{pH}$ for various concentrations of citrate ions. As can be seen, the increase in the citrate ion concentration shifts the edge defining the boundary between the area of yttrium citrate stability and yttrium hydroxide towards higher $\mathrm{pH}$ values. However, taking into account the dissolution reactions of yttrium citrate and in particular, the reaction leading to the formation of soluble forms of yttrium citrate, i.e.: 


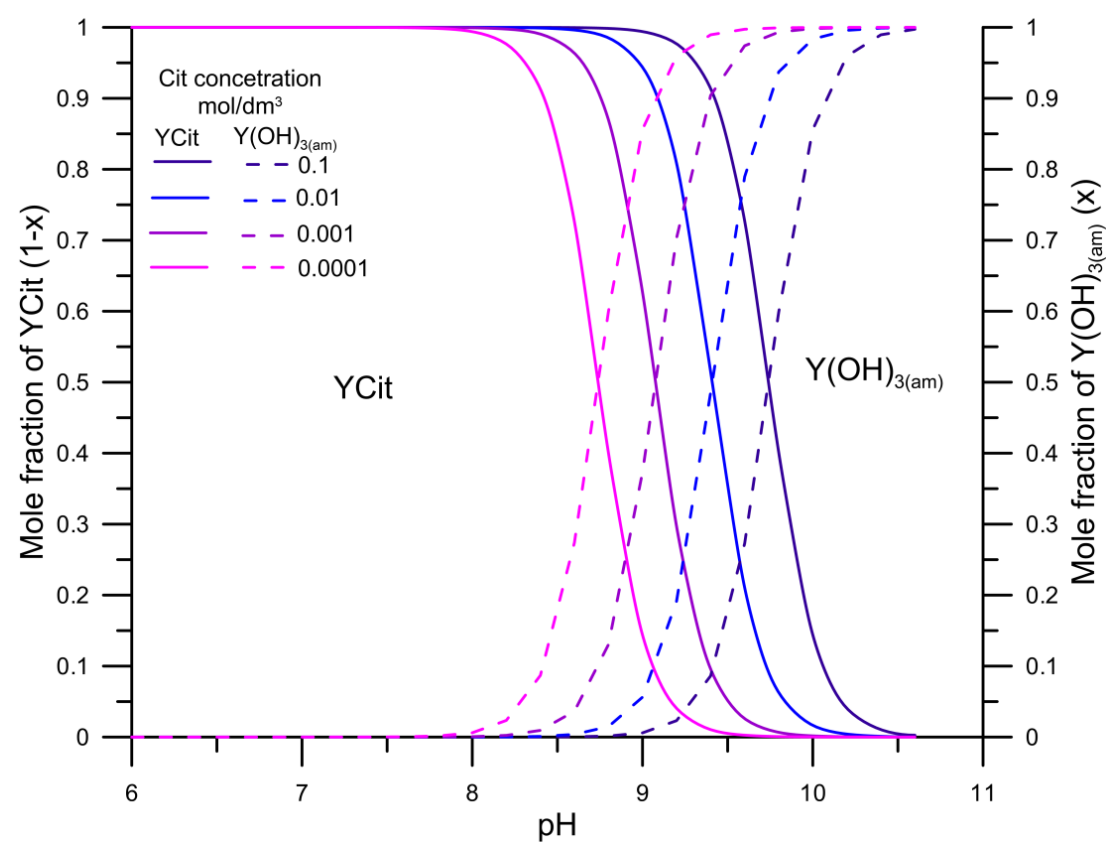

Fig. 1. Mole fractions of yttrium citrate and yttrium hydroxides as a function of $\mathrm{pH}$ and concentration of citrate ions

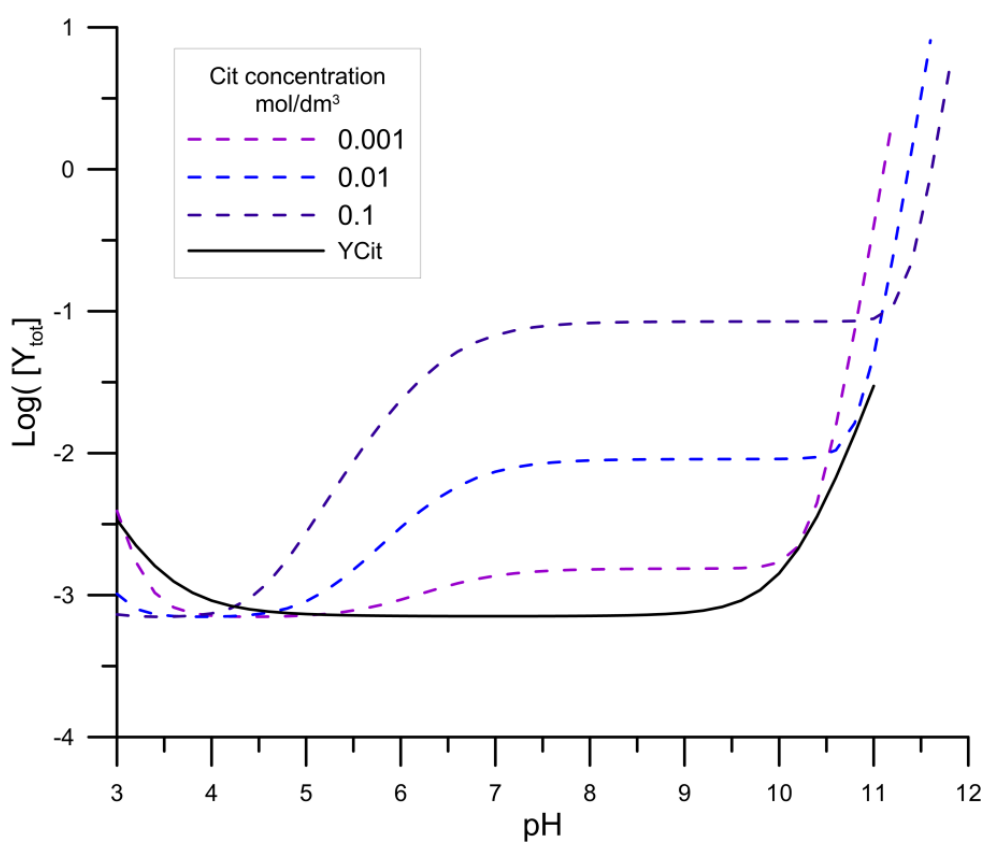

Fig. 2. Effect of citrate ion concentration on the solubility of yttrium citrate (Cit - is the total concentration of citrate form in solution)

$$
\begin{gathered}
\mathrm{YCit} \leftrightarrow \mathrm{Y}^{3+}+\mathrm{Cit}^{3-} \quad \mathrm{p} \beta_{1}=7.87 \text { (Gmelin, 1984) } \\
{\left[\mathrm{Y}(\mathrm{Cit})_{2}\right]^{3-} \leftrightarrow \mathrm{Y}^{3+}+2 \mathrm{Cit}^{3-} \quad \mathrm{p} \beta_{2}=10.95 \text { (Gmelin, 1984) }}
\end{gathered}
$$

an increase in the concentration of citrate ions leads to an increase in the solubility of yttrium citrate in the solutions with a $\mathrm{pH}>5$ along with an increase in the concentration of citrate ions (Fig. 2.) As can be seen in Fig. 2 , the increase in the concentration of citrate ions to the value of $0.001 \mathrm{~mol} / \mathrm{dm}^{3}$ causes a slight increase in the concentration above the solubility of citrate in distilled water, but a further increase in the concentration of citrate ions from $0.001 \mathrm{~mol} / \mathrm{dm}^{3}$ increases the solubility of yttrium citrate significantly. 
This paper presents the kinetics and conditions of transformation of yttrium hydroxide to yttrium citrate in the citrate ion environment.

\section{Materials and methods}

\subsection{Yttrium citrate synthesis}

The first stage of this method was to obtain yttrium hydroxide as an intermediate according to the procedure given by Brzyska (Brzyska, 1987).

\subsection{Yttrium hydroxide preparation}

$\mathrm{YCl}_{3}{ }^{*} 6 \mathrm{H}_{2} \mathrm{O}, \mathrm{Na}_{2} \mathrm{C}_{6} \mathrm{H}_{6} \mathrm{O}_{7} * 1,5 \mathrm{H}_{2} \mathrm{O}$ and $\mathrm{NaOH}$ all analytical grade were supplied by Aldrich and $\mathrm{C}_{6} \mathrm{H}_{8} \mathrm{O}_{7} * \mathrm{H}_{2} \mathrm{O}$ and $\mathrm{Na}_{3} \mathrm{C}_{6} \mathrm{H}_{5} \mathrm{O}_{7} * 2 \mathrm{H}_{2} \mathrm{O}$ both analytical grade by $\mathrm{POCH}$ (Polish Chemical Reagents, Gliwice, Poland). The solutions used in the experiments were prepared using redistilled water. $60 \mathrm{~cm}^{3}$ of a 0.1 $\mathrm{mol} / \mathrm{dm}^{3}$ yttrium chloride solution was placed in a beaker, to which $0.1 \mathrm{~mol} / \mathrm{dm}^{3} \mathrm{NaOH}$ solution was added in small portions until a $\mathrm{pH}$ of about $10(\mathrm{pH}=10.07)$ was reached and a precipitate was formed. Then the resulting precipitate was separated and washed with redistilled water on a membrane filter Synpor no $6(0.4 \mu \mathrm{m})$ to get rid of sodium chloride $(\mathrm{NaCl})$ formed until constant conductivity of the filtrate was obtained. The final conductivity was about $20 \mu \mathrm{S}$.

\subsection{Description of the procedure for obtaining yttrium citrate dihydrate}

$20 \mathrm{~cm}^{3}$ of $0.1 \mathrm{~mol} / \mathrm{dm}^{3}$ sodium citrate solution was prepared from disodium citrate in which washed yttrium hydroxide was dispersed. The suspension was then sonicated for 3 minutes, the $\mathrm{pH}$ was measured and then the suspension was placed in an Autoclave Engineers reactor for a period of 3 days at $80,100,120^{\circ} \mathrm{C}$. The stirrer in the reactor was set at $700 \mathrm{rpm}$ After 6,12, 24,48 and 72 hours the suspension sample was separated and precipitate was washed with redistilled water on a membrane filter Synpor No, $6(0.4 \mu \mathrm{m})$ until constant conductivity of the filtrate was obtained. Conductivity of supernatant after washing out yttrium citrate was measured using Radiometer CDM83 Conductivity Meter with the probe CDC304.The samples of precipitate were dried under the ambient conditions. The obtained yttrium citrate sample was subjected to the structure and particle size analysis as well as TGA.

\subsection{Methods of the samples analysis}

The elemental analysis of the yttrium citrate samples for $\mathrm{C}$ and $\mathrm{H}$ contents was performed using a Perkin-Elmer $\mathrm{CHN}$ analyzer. In addition to the quantitative analysis for the $\mathrm{C}$ and $\mathrm{H}$ contents, the thermogravimetric studies of yttrium citrate samples were carried out using the Q-1500D (MOM, Hungary) apparatus (F. Paulik, J. Paulik, L. Erdey) in the temperature range $20-800^{\circ} \mathrm{C}$ at the heating rate $1 \mathrm{~min}^{-1}$ in the synthetic air atmosphere using a platinum crucible (sample weight $100 \mathrm{mg}$, reference $\mathrm{Al}_{2} \mathrm{O}_{3}$ ). The particle size distribution of the obtained preparations was determined by the method of static light scattering using Malvern's Mastersizer 2000. $\mathrm{pH}$ values were measured using a PHM240 Research pHmeter (G202C and K401 electrodes). pH meter was calibrated using the three buffer solutions: phthalate buffer $\mathrm{pKa}=4.01$, phosphate buffer $\mathrm{pKa}=6.96$ and borate buffer $\mathrm{pKa}=9.18$.

\section{Results and discussion}

The results of the $\mathrm{C}$ and $\mathrm{H}$ analysis of the yttrium citrate sample after 6, 12, 24, 48 and 72 hours of synthesis in the Autoclave Engineers reactor at $120^{\circ} \mathrm{C}$ are shown in Table 1 . The percentage $\mathrm{C}$ decreases with the decreasing $\mathrm{H}$ percentage content after 24 hours and then the $\mathrm{H}$ content stabilizes. The comparison of the carbon content with the theoretically calculated values for yttrium citrate monohydrate and dihydrate indicates that this method gives an intermediate composition i.e. a mixture of yttrium citrate monohydrate and dihydrate. However, the hydrogen content corresponds to the yttrium citrate dihydrate. Considering the carbon content of the samples collected after 48 and 72 hours of synthesis, (Table 1) the content of yttrium citrate dihydrate was calculated, being 77 and $84 \%$, respectively, the remainder can be attributed to the presence of sodium citrate. The results of thermogravimetric analysis of the samples taken during the synthesis are presented in Figs. 3-5. 
Table 1. Results of $\mathrm{C}$ and $\mathrm{H}$ analysis of the dispersion samples taken during the preparation of yttrium citrate at $120^{\circ} \mathrm{C}$ after $6,12,24,48$ and 72 hours of synthesis

\begin{tabular}{|c|c|c|c|c|c|c|c|}
\hline \multirow[t]{2}{*}{ Lp. } & \multirow[t]{2}{*}{ Time [h] } & \multicolumn{2}{|c|}{$\begin{array}{c}\text { Content of elements in the } \\
\text { sample }\end{array}$} & \multicolumn{2}{|c|}{$\begin{array}{l}\text { Calculated content of } \\
\text { elements in } \mathrm{YCit}^{*} \mathrm{H}_{2} \mathrm{O}\end{array}$} & \multicolumn{2}{|c|}{$\begin{array}{l}\text { Calculated content of } \\
\text { elements in } \mathrm{YCit}^{*} 2 \mathrm{H}_{2} \mathrm{O}\end{array}$} \\
\hline & & C [\%] & H [\%] & C [\%] & H [\%] & C [\%] & H [\%] \\
\hline 1. & 6 & 25.71 & 3.24 & \multirow[t]{5}{*}{24.33} & \multirow[t]{5}{*}{2.37} & \multirow[t]{5}{*}{22.93} & \multirow[t]{5}{*}{2.87} \\
\hline 2. & 12 & 24.45 & 3.10 & & & & \\
\hline 3. & 24 & 24.71 & 2.84 & & & & \\
\hline 4. & 48 & 24.70 & 2.84 & & & & \\
\hline 5. & 72 & 24.17 & 2.85 & & & & \\
\hline
\end{tabular}

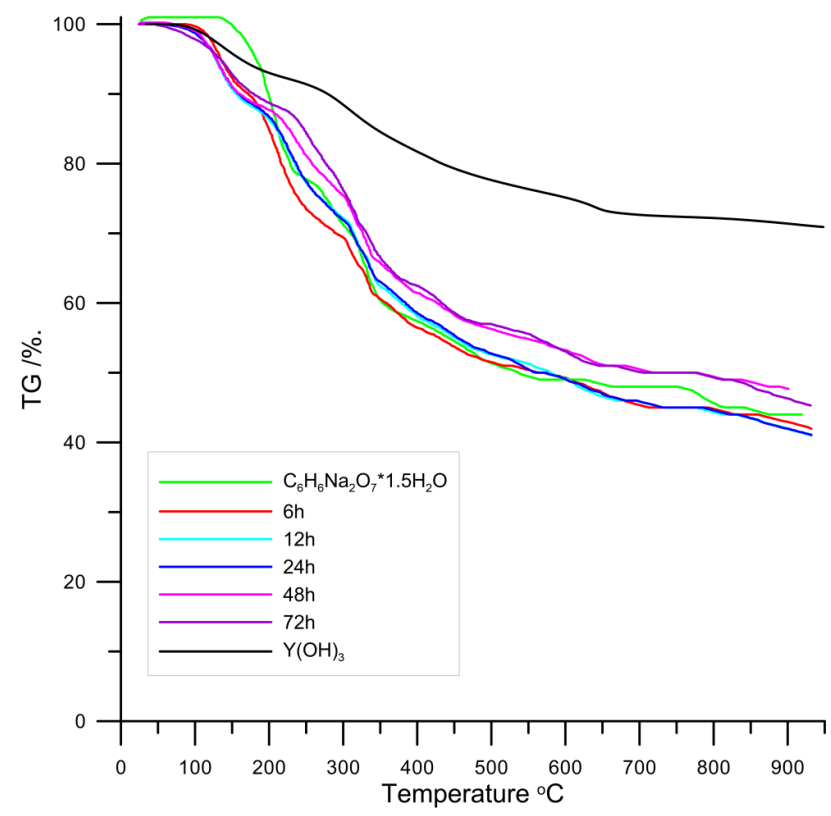

Fig. 3. TG curves of the yttrium citrate samples after 6, 12, 24, 48 and $72 \mathrm{~h}$ synthesis and of the disodium citrate and yttrium hydroxide samples

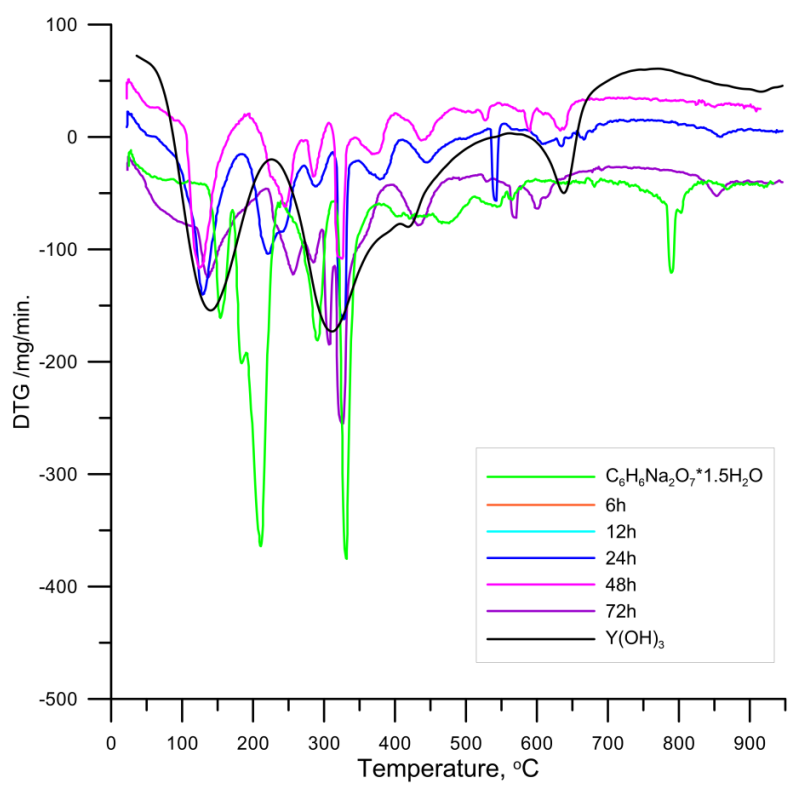

Fig. 4. DTG curves of yttrium citrate samples after 6, 12, 24, 48 and 72h synthesis and of the disodium citrate and yttrium hydroxide samples 


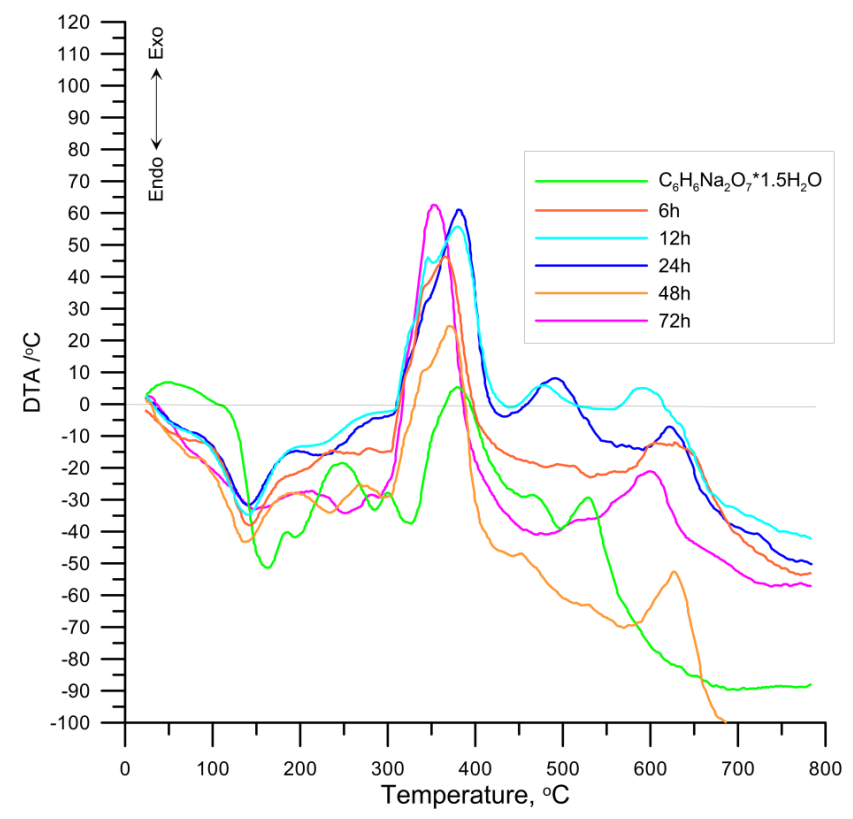

Fig. 5. DTA curves of yttrium citrate samples after 6, 12, 24, 48 and 72h synthesis of the disodium citrate samples

The course of the thermogravimetric analysis curves presented in Figs. 3 and 4 indicates that the decomposition of the tested compounds due to heating is a multi-stage process. Additionally, for comparison, in the figures the course of the thermogravimetric curves for disodium citrate and yttrium hydroxide as the reference systems (initial reagents) is presented. No weight loss associated with the loss of hygroscopic water was observed on the TG curve of disodium citrate up to $133^{\circ} \mathrm{C}$. Above this temperature up to $171^{\circ} \mathrm{C}$ there is a slight weight loss $(\sim 4 \%)$ which corresponds to a loss of 0.5 mole of water per 1 mole of hydrated disodium citrate. In the temperature range of $171-242^{\circ} \mathrm{C}$ there is a $19 \%$ weight loss, including the temperature range on the DTG curve, (Fig. 3). There are two peaks close together, one of which may be associated with the loss of one molecule of crystallization water, the other with dehydration of citrate ions and the formation of anions of aconitic acids and their anhydrides. After calculating the weight loss, the dehydration process will be associated with the release of 1.75 water molecules. In the next stage of hydrated disodium citrate decomposition in the temperature range 243$314^{\circ} \mathrm{C}$, a loss of $8 \%$ by weight occurs which may be associated with further dehydration of aconitic acids and their anhydrides (Wyrzykowski et al., 2011). A further weight loss associated with the release of carbon dioxide and oxidation of residual carbon from decomposition occurs above $314^{\circ} \mathrm{C}$. Thus, thermal effects associated with the exothermic processes are observed on the DTA curve (Fig. 5.) It is not excluded that the release of carbon dioxide and the combustion of elemental carbon may be accompanied by the release of water due to decomposition of sodium citrate above $169^{\circ} \mathrm{C}$ (Wiecinska et al., 2016). Heating a sample of hydrogen disodium citrate sesquihydrate above a temperature of $860^{\circ} \mathrm{C}$ does not change the sample mass (44\% of the initial mass remains), which indicates the end of the compound decomposition. The residue after the sodium citrate decomposition is close to the $\mathrm{Na}_{2} \mathrm{CO}_{3}$ content of the $\mathrm{Na}_{2} \mathrm{Cit} * 1.5 \mathrm{H}_{2} \mathrm{O}$ sample. The PXRD analysis of the disodium citrate residue heated to $900^{\circ} \mathrm{C}$ showed that the peaks on the diffraction pattern correspond to the peak positions of the PDF 00037-0451 sodium carbonate sample card.

As the temperature increases, decomposition of yttrium hydroxide involves four stages of physically adsorbed water loss in the temperature range up to $225^{\circ} \mathrm{C}$, then the transformation of yttrium hydroxide into yttrium oxyhydroxide from 225 to $408^{\circ} \mathrm{C}$ takes place followed by the decomposition of yttrium oxyhydroxide to yttrium oxide from 408 to $637^{\circ} \mathrm{C}$. The fourth stage is related to the decomposition of yttrium carbonate which was formed by the reaction of adsorbed carbon dioxide with yttrium hydroxide, the peak at $638^{\circ} \mathrm{C}$.

The TG curves for the samples were taken after 6, 12 and 24 hours. The syntheses above $200^{\circ} \mathrm{C}$ run close to the TG curve of disodium citrate. After heating the samples taken above $600^{\circ} \mathrm{C}, 41,40$, and $40 \%$ of the initial mass remain respectively. This indicates that in addition to the yttrium oxide resulting 
from the decomposition of yttrium hydroxide or/and yttrium citrate, some sodium carbonate may be present in the residue as a product of sodium citrate decomposition. Determination of the residue composition is difficult based on the TG analysis due to the content of physically adsorbed water in the analyzed samples. The presence of unreacted sodium citrate in the samples is confirmed by the results of the analysis for the $\mathrm{C}$ and $\mathrm{H}$ contents presented in Table 1 . The course of the TG curves for the samples taken after 48 and 72 hours of synthesis above $200^{\circ} \mathrm{C}$ indicates a several percent higher solid content in the samples (Fig. 3.) The comparison of the course of DTG curves for the samples taken after 48 and 72 hours of synthesis with the DTG curve of disodium citrate indicates a decrease in peaks at 211 and $331^{\circ} \mathrm{C}$ and the appearance of new peaks at higher temperatures, i.e. at 432,567 and $602^{\circ} \mathrm{C}$, Fig. 4 . From a sample taken after the 72 hour - synthesis after heating above $700^{\circ} \mathrm{C}$ there remain $34 \%$ of the initial mass which corresponds approximately to the composition of yttrium citrate dihydrate.

The course of TG and DTG curves of this sample is confirmed by the multi-stage decomposition of hydrated yttrium citrate observed by Todorovski et al. (Todorovski et al., 2006), although the temperature range of individual stages in Fig. 4 is different. This difference may be related to different synthesis and consequently to the resulting product. Todorowsky et al. synthesized in ethyl glycol and obtained yttrium citrate monohydrate. The TG curve is shown in Fig. 3 for the sample taken after 48 and 72 hours. The synthesis indicates that the decomposition takes place in many stages. Nine peaks can be seen in Fig. 4. After heating the sample to $124^{\circ} \mathrm{C}$, there is a $4 \%$ weight loss at $224^{\circ} \mathrm{C}-82 \%$ of the initial mass is left, $297^{\circ} \mathrm{C}-77 \%$, at $455^{\circ} \mathrm{C}-48 \%$ at $535^{\circ} \mathrm{C} 41 \%$ of the initial mass. The comparison of the DTA curve of disodium citrate decomposition with those of 48 and 72 hours samples indicates the disappearance of the double peak in the temperature range $171-242^{\circ} \mathrm{C}$ and the appearance of several peaks in the temperature range $400^{\circ} \mathrm{C}-650^{\circ} \mathrm{C}$. The complex course of sample decomposition indicates that the obtained sample may be a mixture of yttrium citrate monohydrate and dihydrate. The course of DTA curves in Fig 5 indicates that up to $300^{\circ} \mathrm{C}$ decomposition processes are endothermic, whereas above that - exothermic. The analysis of $\mathrm{C}$ and $\mathrm{H}$ content and the residue after heating the sample to $960^{\circ} \mathrm{C}$ indicates the presence of approximately unreacted $\sim 16 \pm 3 \%$ disodium citrate and $\sim 3 \pm 2 \%$ yttrium hydroxide.

Table 2. Characteristics of the samples obtained under different temperature and $\mathrm{pH}$ conditions of the solution

\begin{tabular}{|c|c|c|c|c|c|c|}
\hline \multirow{2}{*}{$\begin{array}{c}\text { Sample } \\
\text { no }\end{array}$} & Solution & pH & \multirow{2}{*}{\begin{tabular}{c} 
Tmep. \\
\cline { 5 - 7 }
\end{tabular}} & & & \multicolumn{2}{c|}{ Composition } & Size \\
\hline 1 & & & $\mathrm{C}[\%]$ & $\mathrm{H}[\%]$ & \\
\hline 2 & $0.1 \mathrm{M} \mathrm{Na}_{3} \mathrm{Cit}$ & 10.26 & 100 & 25.0 & 2.00 & $0.1-0.9,0.9-4 \mu \mathrm{m}$ \\
\hline 3 & $0.1 \mathrm{M} \mathrm{Na}_{3} \mathrm{Cit}+0.1 \mathrm{M} \mathrm{H}_{3} \mathrm{Cit}$ & 5.95 & 100 & 24.9 & 2.8 & \\
\hline 4 & $0.1 \mathrm{M} \mathrm{Na}_{2} \mathrm{HCit}$ & 10.15 & 120 & 24.2 & 2.8 & \\
\hline 5 & $0.1 \mathrm{M} \mathrm{Na}_{2} \mathrm{HCit}$ & 5.56 & 100 & 24.7 & 2.6 & \\
\hline
\end{tabular}

Table 2 presents the characteristics of the samples obtained under different temperature and $\mathrm{pH}$ conditions. The comparison of the $\mathrm{C}$ and $\mathrm{H}$ contents obtained from the $\mathrm{CHN}$ analysis for individual samples with the theoretical contents of both elements in $\mathrm{YCit}{ }^{*} \mathrm{H}_{2} \mathrm{O}(24.3 \% \mathrm{C}$ and $2.37 \% \mathrm{H})$ indicates that the obtained compound may be yttrium citrate hydrate. Only in the case of sample No. 6 the contents of $\mathrm{C}$ and $\mathrm{H}$ are larger which may indicate a residual $\mathrm{Na}_{2} \mathrm{HCit}+\mathrm{H}_{3} \mathrm{Cit}$ reagent in the obtained precipitate.

The PXRD analysis of the obtained samples showed that only in the case of sample \# 1 a crystalline precipitate was obtained while the other samples were amorphous. The diffraction pattern analysis of sample No. 1 showed that besides the characteristic peaks of yttrium citrate, the unreacted substrates, i.e. disodium citrate and yttrium hydroxide may appear in the sediment. The results in Table 2 point out that the optimal conditions for the synthesis of yttrium citrate are the use of yttrium hydroxide and disodium citrate as substrates, a reaction temperature of $120^{\circ} \mathrm{C}$, a reaction time of at least 3 hours.

Fig. 6 presents the results of particle size analysis of the samples obtained in syntheses Nos. 1 and 5, for the remaining samples no grain analysis was performed due to the consumption of sample No. 3 in the kinetic studies, and in the case of samples 2, 3 and 8, they were dissolved affected by the ultrasound. The particle size distribution of the sample obtained in synthesis No. 1 is bimodal with a $45 \%$ volume 
fraction of particles from 0.13 to $0.9 \mu \mathrm{m}$ and the other $56 \%$ volume fraction of particles from 0.9 to $5 \mu \mathrm{m}$. The sample particles obtained in synthesis No. 5 also have a bimodal distribution but both fractions overlap and can be only estimated by deconvolution from a particle size range of one fraction from 1 to $14 \mu \mathrm{m}$ and the other from $14-140 \mu \mathrm{m}$.

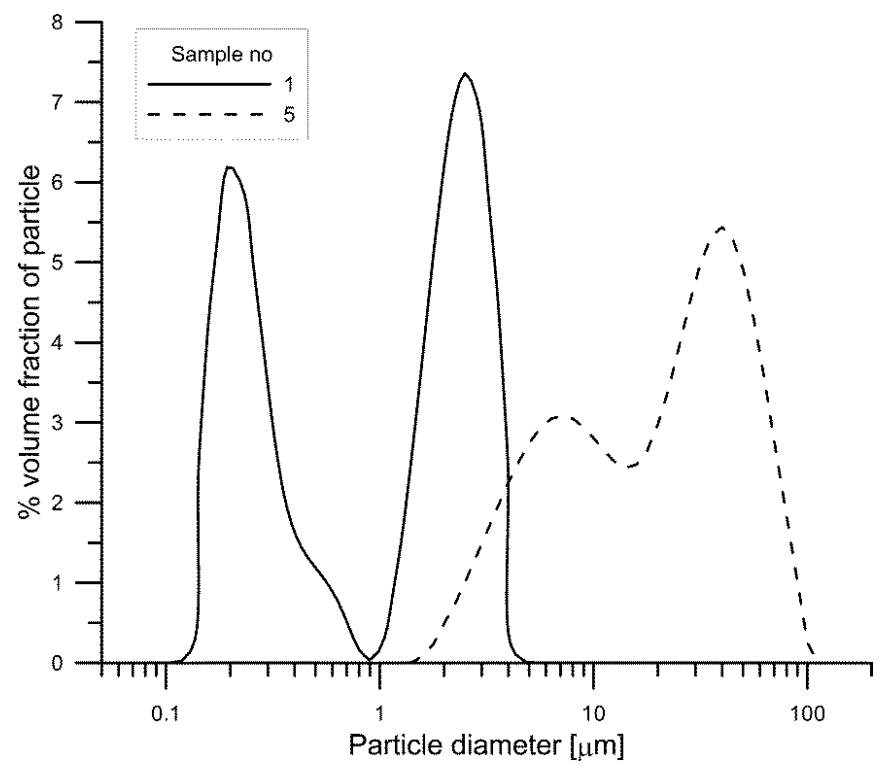

Fig. 6. Particle size distribution of the yttrium citrate samples prepared in syntheses Nos 1 and 5

\section{Conclusions}

The results of the study presented in this paper can be summarized as follows:

- Amorphous yttrium citrate monohydrate was obtained by transformation of freshly precipitated yttrium hydroxide in the sodium citrate solutions under hydrothermal conditions. The analysis of $\mathrm{CN}$ composition showed that the optimal temperature for the transformation of yttrium hydroxide in the disodium hydrogen citrate solution is $100^{\circ} \mathrm{C}$.

- The thermogravimetric analysis indicates that the decomposition of hydrogen disodium citrate sesquihydrate due to heating takes place in four stage. Initially, the weight loss of the sample is related to the release of crystallization water, then with the dehydration of the citrate ion and oxidation of dehydration products and as the final product sodium carbonate is formed.

- The thermogravimetric analysis of the samples taken during the reaction of disodium hydrogen citrate with yttrium hydroxide indicates that in the initial period, up to 24 hours, adsorption of disodium citrate on yttrium hydroxide occurs. After this period, a reaction occurs to form yttrium citrate dihydrate.

- The thermogravimetric analysis of the amorphous yttrium citrate sample showed that the decomposition/oxidation of the sample occurs in six stages. In the first stages, the adsorption of water and physically adsorbed carbon dioxide occurs, and then the crystallization water is released, followed by dehydration of citrate and its combustion.

- The advantage of the proposed method, compared to those reported in the literature, is the shorter synthesis time (3 days), but optimization of the parameters in order to reduce the non-reacting substrates content is time consuming.

\section{Acknowledgments}

The authors would like to thank Prof. dr hab. Renata Mikołajczak and Prof. dr hab. Józef Parus from Radioisotope Centre Polatom for reviewing the manuscript and providing very useful comments.

\section{References}

BABESHKINA, Z M.; MARTYNENKO, L. I., 1966. About Yttrium Citrate (Russian text). Zhurnal Neorganicheskoi Khimii, 11, 1046 - 1047. 
BABESHKINA, Z. M., MARTYNENKO, L. I., GRIGOR'EV, A. I., 1966. About Hydroxy Rare Earth Elements Citrate (Russian text). Zhurnal Neorganicheskoi Khimii. 11, 685 - 690.

BAGGIO, R., PEREC M., 2004. Isolation and characterization of a Polymeric Citrate. Inorg. Chem. 43, 6965-6968.

BOWEN, B. M., DARRACOTT, J., GARNETT, E.S., TOMLINSON, R. H., 1975. Yttrium-90 citrate colloid for radioisotope synovectomy. Amer. J. Pharm. 32, 1027-30.

BLOCK, L., DE BRUYN, P.L., 1970. The Ionic Double Layer at the ZnO Solution Interface. II Composition Model of the Surface. J Colloid Interface Sci. 32, 527-532.

BRZYSKA, W., 1987. Lantanowce i aktynowce. WNT, Warszawa, Poland

CHEN, J., HUANG, B., HUANG, C., SUN, X., 2017. Preparation of nanoscaled yttrium oxide by citrate precipitation method. J. Rare Earths, 35, 79-84.

Eur. J. Nucl. Med., 2003. 30:BP12-BP16.

FEITKNECHT, W., SCHINDLER, P., 1963. Solubility constants of metal oxides, metal hydroxides and metal hydroxide salts in aqueous solution. Pure Appl. Chem., 6(2), 125-206.

GMELIN Handbook of Inorganic Chemistry -8th Edition, 1984. Springer Verlag, Berlin, 344-358.

HEUFT-DORENBOSCH, L. L J, DE VET, H. C. W., VAN DER LINDEN, S., 2000. Yttrium radiosynoviorthesis in the treatment of knee arthritis in rheumatoid arthritis: a systematic review. Ann. Rheum. Dis. 59, 583-586.

MANGALARAJAA, R.V., MOUZONB, J., HEDSTROMB, P., KEROB, I., RAMAMA, K.V.S., CARLOS, P. CAMURRIA, M., OD’ENB., 2008. Combustion synthesis of Y2O3 and Yb-Y2O3 Part I. Nanopowders and their characterization. J. Mater. Process. Technol., 208, 415-422.

MATIJEVIC, E., 1986. Monodispersed Colloids: Art and Science, Langmuir 2, 12-20.

PETROVA, N., TODOROVSKY, D., 2006. Thermal decomposition of zirconium-yttrium citric complexes prepared in ethylene glycol and water media. Mater. Res. Bull. 41, 576-589.

SUGIMOTO, T., 2002. Mechanisms of Nucleation and Growth of Monodispersed particles. In Encyclopedia of Surface and Colloid Science (Hubard Ed.) Marcel Dekker Inc. New York.

WIECINSKA, P., 2016. Thermal degradation of organic additives used in colloidal shaping of ceramics investigated by the coupled DTA/TG/MS analysis. J Therm Anal Calorim 123, 1419-1430.

WYRZYKOWSKI, D., HEBANOWSKA, E., NOWAK-WICZK, G., MAKOWSKI, M., CHMURZYNSKI, L., 2011. Thermal behavior of citric acid and isomeric aconitic acids. J Therm Anal Calorim 104, 731-735.

VISWANATHA, R., SARMA, D.D., 2007. Growth of Nanocrystals in Solution. Nanomaterials Chemistry. C.N.R. Rao, A. Mu“ller, and A.K. Cheetham Eds, WILEY-VCH Verlag GmbH \& Co. KGaA, Weinheim.

ZHONG, S., WANG, S., LIU, Q., WANG, Y., WANG, S.H., CHEN, J., XU, R., LUO, L., 2009. Y Y $O_{3}$ :Eu3+ microstructures: Hydrothermal synthesis and photoluminescence properties. Mater. Res. Bull. 44, 2201-2205.

ZHOU, R.S., SONG, J.F., YANG, Q.F., XU, X.Y., XU, J.Q., WANG, T.G., 2008. Syntheses, structures and magnetic properties of a series of $2 \mathrm{D}$ and $3 \mathrm{D}$ lanthanide complexes constructed by citric ligand. J. Molecular Struct. 877, 115-122. 